\title{
Potencializando a programação de jogos digitais de matemática através do Scratch e da avaliação Game Flow
}

\author{
Cintia Shimohara $^{1}$, Elaine Silva Rocha Sobreira ${ }^{2}$, Olavo Ito $^{3}$ \\ ${ }^{1}$ Professora de matemática, ${ }^{2 \text { e }}{ }^{3}$ Equipe de tecnologia - Centro Educacional Pioneiro \\ São Paulo - SP - Brasil \\ ${ }^{2}$ Programa de Pós-Graduação Multiunidades em Ensino de Ciências e Matemática - \\ Universidade Estadual de Campinas, Unicamp - Campinas, SP, Brasil \\ ${ }^{3}$ ICET Instituto de Ciências Exatas e Tecnologia - Unip - São Paulo, SP, Brasil \\ cintia@pioneiro.g12.br, elaine@pioneiro.g12.br, olavo@pioneiro.g12.br
}

\begin{abstract}
The creation of digital games associated with math content can promote the development of learning both related to mathematical knowledge, as well as the development of a digital literacy. In order to assist elementary students to create games to other classmates which were challenging and attractive, and at the same time involve the curriculum content significantly, providing a reflection on the aspects of gameplay, through an adapted evaluation from the GameFlow method, making it accessible to students from elementary school, which they analyzed mathematical games in order to improve the production of their own games.
\end{abstract}

Resumo. A criação de jogos digitais associado ao conteúdo de matemática pode favorecer o desenvolvimento de aprendizados tanto relacionados aos saberes matemáticos, quanto ao desenvolvimento de um letramento digital. Com o objetivo de auxiliar os alunos do ensino fundamental I a criarem jogos para os colegas que fossem desafiadores e atrativos, e que ao mesmo tempo envolvesse os conteúdos curriculares de forma significativa, proporcionamos uma reflexão sobre os aspectos relacionados à jogabilidade, através de uma avaliação adaptada do método GameFlow, tornando-o acessível aos alunos do fundamental I, onde analisaram jogos matemáticos para melhorar a produção dos seus próprios jogos.

\section{Introdução}

O trabalho com linguagens de programação vem sendo difundido no ensino fundamental, como uma importante estratégia para desenvolvimento do letramento digital, pois, para os alunos da sociedade atual, já não é suficiente apenas o simples consumo ou manuseio mecânico dos produtos disponíveis no mercado, busca-se cada vez mais 0 desenvolvimento de indivíduos que sejam capazes de saber lidar com a diversidade de situações do cotidiano e possam agir sobre elas, solucioná-las e transformá-las (Sobreira et. all, 2013).

Os jogos digitais já vêm sendo utilizados na educação, tanto como recursos que aliam a ludicidade a um potencial educativo, quanto como criação e produção autoral 
através da programação de jogos (Shimohara e Sobreira, 2015). Isso tornou-se possível graças ao desenvolvimento de linguagens adequadas para que as próprias crianças façam a programação. É o caso, por exemplo, do Scratch, que proporciona a criação de animações, simulações e jogos, dentre outros, de modo que os alunos não apenas utilizam as tecnologias prontas, eles criam e desenvolvem novas aprendizagens nesse processo. Maltempi e colaboradores (2015) defendem o uso de softwares como o Scratch, pois favorece a compreensão de como os ambientes pertencentes às tecnologias digitais se relacionam com a matemática.

Reconhecendo o potencial da programação para a criação de jogos no ensino de matemática, desenvolveu-se a proposta com 3 turmas do $5^{\circ}$ ano do ensino fundamental I, essa proposta desafiou os alunos a avaliar jogos de outra autoria, para refletir sobre os aspectos que envolvem a criação de narrativa e programação de jogos digitais, obtendo embasamentos para criação de um interessante jogo digital de matemática.

Após essa análise, os alunos criaram um roteiro do jogo, programaram e avaliaram seus próprios jogos, de modo a detectar se houve intenção de mudança e efetivação de pontos observados como necessários para a criação de um jogo atrativo e desafiador.

Para a avaliação dos jogos foi utilizada como base a teoria de GameFlow criada por Sweetser e Wyeth (2005, apud Fu, 2009) e utilizada por Silva e colaboradores (2015), Neves e colaboradores (2014), Bittencourt e colaboradores (2015) e Medeiros e Schimiguel (2012). Para esse trabalho, foram realizadas adaptações necessárias para compreensão dos alunos com faixa etária entre 9 e 10 anos.

A estrutura deste artigo está organizada da seguinte forma: na seção 2, apresentam-se alguns trabalhos relacionados; na seção 3, discute-se a programação de jogos com Scratch associado à criação de problemas de matemática; na seção 4 discutese a avaliação de jogos à partir da teoria GameFlow, seguido na seção $4.1 \mathrm{com}$ a apresentação dos critérios elencados para a avaliação de jogos por alunos do ensino fundamental I; na seção 5 descreve-se o desenvolvimento do trabalho em sala de aula, a partir da análise, criação e programação de jogos de matemática; nas seções 6 e 7 apresentam-se os resultados, as considerações finais e a possibilidade de trabalhos futuros; e, por fim, a seção 8 traz as referências.

\section{Trabalhos relacionados}

Este trabalho contempla as vertentes de programação de jogos de matemática e avaliação de jogos digitais por alunos dos anos iniciais do ensino fundamental. Em relação à programação de jogos de matemática, Shimohara e Sobreira (2015) relatam a experiência de um trabalho colaborativo entre os alunos, que envolveu a criação de jogos digitais, incluindo a criação de desafios de matemática, o que favoreceu o desenvolvimento de habilidades próprias do trabalho de programação, além de aliar o poder motivador dos jogos à criação de desafios.

Em relação à vertente de avaliação de jogos, diversos trabalhos foram realizados buscando avaliar jogos para contextos educativos através da teoria Flow. Como exemplo temos, Neves et. all (2014) que analisa a utilização do método GameFlow, propondo algumas alterações com o objetivo de contemplar as especificidades desses jogos para avaliação de três jogos sérios casuais, constatando que o método é aplicável. 
O trabalho de Bittencourt et. all (2015) apresenta a avaliação de dois jogos de matemática. Essa avaliação leva em consideração as perspectivas do modelo GameFlow, Lori e Kirkpatrick, focado em perspectiva qualitativa e quantitativa.

Medeiros e Schimiguel (2012), utiliza alguns critérios da metodologia LORI e outros critérios da metodologia GameFlow para avaliação do jogo "Stop", pois acredita que a LORI avalia a qualidade de um objeto educacional, mas não consegue alcançar as particularidades necessárias para avaliar a qualidade de um jogo eletrônico educacional, enquanto a GameFlow é uma proposta de avaliação do nível de prazer oferecido pelo jogo eletrônico para o jogador.

Silva (2015) propõe diretrizes de avaliação para auxiliar o docente na seleção de jogos para o ensino de programação baseada em técnicas de engajamento, perfis de jogadores e características do estado de Flow. Para isso, analisa três jogos seguindo a teoria de Flow, além de avaliar técnicas de engajamento e perfis de jogadores.

Neste contexto, o diferencial do presente trabalho está na avaliação de jogos feita por alunos do ensino fundamental I, com o intuito de melhorar a qualidade dos jogos criados e programados por eles mesmos quando, em um momento anterior, atenderam à proposta de criação de jogos de matemática para o desenvolvimento da produção de desafio e letramento digital. Por ser uma avaliação realizada por alunos com idade de 10 anos, optamos apenas pela avaliação GameFlow, pois os alunos não teriam conhecimentos pedagógicos para avaliar os jogos com parâmetros da avaliação LORI.

\section{Programação de jogos com Scrath integrados à criação de problemas em matemática}

O Scratch é uma linguagem de programação própria para crianças por utilizar uma linguagem baseada em blocos de encaixe que eliminam possíveis erros de sintaxe, facilitando assim a conexão correta dos comandos. Permite o desenvolvimento de animações, simulações, jogos digitais, dentre outros. Foi desenvolvido por Mitchel Resnick e sua equipe no Lifelong Kindergarten Group no Media Lab do Instituto de Tecnologia de Massachusetts (MIT). É livre e está disponibilizado gratuitamente para multiplataformas, podendo ser utilizado offline nas versões Scratch 1.4 e Scratch 2.0 offline, além de permitir criação online através da página: https://scratch.mit.edu/

O Scratch é acessível para alunos tanto do ensino fundamental (Shimohara e Sobreira, 2015) quanto do ensino médio (Ramos e Teixeira, 2015). Em sua análise, Ramos e Teixeira (2015) observaram que os alunos de turmas da educação básica "são capazes de interagir e produzir objetos digitais num ambiente de linguagem de programação, mesmo sem conhecimentos prévios específicos da área da computação, e ainda num espaço reduzido de tempo" (Ramos e Teixeira, 2015 p.225).

Compreendendo a possibilidade de criação dos alunos do ensino fundamental I, e a facilidade proposta pela programação com Scratch, optou-se pelo uso deste recurso para viabilizar a criação de desafios de matemática motivados no contexto de programação de jogos digitais, através de uma proposta onde os alunos pudessem ser autores tanto dos jogos, quanto dos problemas matemáticos, incentivando a criação e a resolução de problemas. Isso estimulou o estudo e criação de problemas com mais de uma operação, enunciados elaborados, pois seriam resolvidos por outros estudantes. 
Pólya (2003, apud Pinto,2010) vai mais longe ao considerar que o principal objetivo da educação é desenvolver nos mais novos a capacidade de pensar, considerando, deste modo, a resolução de problemas como uma arte que todos podem aprender.

A resolução de problemas pode contribuir não só para desenvolver a competência matemática, mas também para o desenvolvimento de competências essenciais na formação global dos alunos, Vale (1997, apud Pinto, 2010).

Com intuito de fazer jogos prazerosos e desafiantes, propomos aos alunos fazer uma avaliação dos jogos do ano anterior e que refletissem como poderiam aprimorar a programação dos futuros games e formular problemas matemáticos mais desafiadores.

\section{Avaliação de jogos - GameFlow}

Para viabilizar a produção criativa de jogos, faz-se necessário analisar quais aspectos envolvem os jogos atrativos, para isso, buscamos referências de pesquisas que analisam o equilíbrio entre desafio e habilidade associadas ao prazer em executar a tarefa proposta. O psicólogo húngaro Mihaly Csikszentmihalyi, pesquisou durante anos o sentimento de experiência agradável das pessoas, com o objetivo de identificar os aspectos que favorecem a harmonia entre mente e corpo fornecendo ao indivíduo a sensação de felicidade. $\mathrm{O}$ estado de equilíbrio entre a habilidade e o desafio da tarefa executada, o qual leva a sensação de felicidade foi denominada como estado de "Flow".

Segundo Mihaly Csikszentmihalyi (1993), o termo "Flow", descreve o sentimento da experiência mais agradável, o que não acontece durante momentos relaxantes de lazer e entretenimento, mas sim quando estamos ativamente envolvidos em uma tarefa que exige habilidades físicas ou mentais. Ocorre quando os desafios são elevados e as habilidades pessoais são utilizadas ao máximo, levando a um estreitamento de atenção sobre uma meta claramente definida.

Fu (2009) descreve que o conceito de Flow foi aplicado em pesquisas sobre desenvolvimento de jogos, até que Sweetser e Wyeth (2005, apud Fu, 2009) utilizaram esses conceitos para integrar e sintetizar a literatura existente sobre jogos de computador e, posteriormente, desenvolveram o " GameFlow ", uma série de critérios que podem ajudar os designers a medir o potencial de um jogo. Sweetser e Wyeth "apresentaram resultados eficientes no processo de avaliação de jogos, sendo, por isso, a base para o desenvolvimento de outros métodos e modelos" (Neves et. all, 2014, p.46)

O GameFlow consiste em uma avaliação com o propósito de verificar o nível de prazer de um jogo, facilitando assim a aplicação de melhorias no design ( $\mathrm{Fu}, 2009)$.

Bittencourt (2015) relaciona os itens de análise do GameFlow:

Essa avaliação é composta por alguns critérios Concentração: Jogos devem exigir concentração; Desafio: Jogos devem ser desafiadores e corresponderem ao nível de habilidade do jogador; Habilidade do Jogador: Jogos devem apoiar o desenvolvimento da habilidade do jogador; Controle: O jogador deve ter sensação de controle sobre suas ações no jogo; Objetivos Claros: Jogos devem fornecer metas claras ao jogador; Feedback: O jogador deve receber feedback adequado em momentos apropriados; Imersão: $\mathrm{O}$ jogador deve ter envolvimento profundo; e Interação Social: Jogos devem apoiar e criar oportunidades de interação social. (Bittencourt, 2015, p. 656) 
Diante desses itens, organizamos um formulário de avaliação, buscando ao mesmo tempo, contemplar as características de avaliação do GameFlow e utilizar uma linguagem compreensível aos alunos.

\subsection{Formulário de avaliação de jogos para alunos do Ensino Fundamental I}

Para adequar ao público que iria utilizar a avaliação (alunos entre 9 e 10 anos) e, considerando que a atividade não poderia ser muito longa nem cansativa para o público, unimos alguns blocos criando os seguintes itens avaliativos:

- Concentração e tempo do jogo (referente às dimensões concentração e imersão);

- Desafios dos jogos (referente à dimensão desafio)

- Habilidades do jogador (referente às dimensões habilidade do jogador e controle)

- Objetivos e respostas do jogo (referente às dimensões objetivos claros e feedback)

- Interação (referente à dimensão interação social)

Para cada critério foram desenvolvidas as questões relacionadas na tabela 1:

Tabela 1. Dimensões e questões criadas para avaliação dos jogos adaptado do GameFlow para os alunos do ensino fundamental I

\begin{tabular}{|l|l|}
\hline Dimensões: & Perguntas para análise: \\
\hline $\begin{array}{l}\text { Concentração e } \\
\text { tempo do jogo }\end{array}$ & $\begin{array}{l}\text { Você se concentrou no jogo? } \\
\text { O jogo chamou sua atenção? } \\
\text { Conseguiu ficar atento para resolver os desafios? } \\
\text { Você quis jogar até o fim? } \\
\text { Quando acabou o jogo, você queria jogar mais? } \\
\text { O tempo do jogo foi bom? } \\
\text { O jogo foi divertido? }\end{array}$ \\
\hline Desafios dos jogos & $\begin{array}{l}\text { Foi possível responder aos desafios de matemática? } \\
\text { No decorrer do jogo a dificuldade dos desafios de matemática aumentou? }\end{array}$ \\
\hline $\begin{array}{l}\text { Habilidades do } \\
\text { jogador }\end{array}$ & $\begin{array}{l}\text { Você precisou ler algum manual antes de jogar? } \\
\text { Você conseguiu compreender as regras? } \\
\text { Foi divertido aprender a jogar? } \\
\text { Teve alguma ajuda durante o jogo? } \\
\text { Você foi recompensado pelo seu esforço no decorrer do jogo? } \\
\text { Quando você errou teve alguma dica para acertar? } \\
\text { Resolver os desafios foi importante para finalizar o jogo? }\end{array}$ \\
\hline $\begin{array}{l}\text { Interação } \\
\text { Objetivos e respostas }\end{array}$ & $\begin{array}{l}\text { Desde o início você entendeu o que era para ser feito no jogo? } \\
\text { Durante o jogo é possível saber se você está indo bem ou mal? } \\
\text { Ao responder um desafio você consegue saber se acertou ou errou? } \\
\text { É possível saber qual foi a sua pontuação? }\end{array}$ \\
\hline $\begin{array}{l}\text { É possível jogar com mais de um jogador? } \\
\text { O jogo permite competição entre os jogadores? } \\
\text { O jogo tem cooperação entre os jogadores? }\end{array}$ \\
\hline
\end{tabular}


V Congresso Brasileiro de Informática na Educação (CBIE 2016)

Anais do XXII Workshop de Informática na Escola (WIE 2016)

\section{Desenvolvimento da análise, criação e programação de jogos de matemática}

Para o desenvolvimento do trabalho, o primeiro desafio foi a escolha do tema do jogo. Os alunos optaram por temas de filmes e, realizaram uma eleição para escolha. Com o resultado final, os alunos do $5^{\circ}$ ano $\mathrm{A}$, programaram jogos com o tema Pixels e os alunos das turmas $5^{\circ} \mathrm{B}$ e $\mathrm{C}$ escolheram programar com o tema Star Wars.

Para que os alunos pudessem criar um jogo divertido e desafiador, verificou-se a necessidade de analisar aspectos técnicos de um jogo relativos à jogabilidade e aspectos específicos dos conteúdos. Com esse objetivo, os alunos avaliaram um jogo digital de matemática programado pela turma do $5^{\circ}$ ano de 2015 , utilizando as questões contidas na tabela 1, seguida de uma discussão verificando os aspectos que poderiam ser modificados, com o intuito de tornar o jogo mais atrativo e planejar as características da narrativa de seus próprios jogos.

Concomitantemente, para criação dos desafios de matemática, os alunos reuniram-se em duplas ou trios a fim de formular os problemas, para os quais as duplas criaram dois desafios matemáticos, e o trio criou três.

Os alunos estão habituados a resolver problemas de Matemática, mas desta vez, receberam a orientação de serem autores de desafios de Matemática para serem programados em jogos digitais. Os alunos puderam consultar o livro didático, ficha de atividades e caderno de exercícios.

Em cada turma, foram utilizadas três aulas de Matemática para elaboração dos desafios que totalizaram mais de 73 . Os alunos iniciaram a programação dos jogos utilizando Scratch, pesquisando outros jogos existentes, com desafios semelhantes, de modo que pudessem observar a programação existente obtendo parâmetros para criar sua própria programação. Também utilizaram a estratégia de remixagem de personagens e alguns comandos. Em cada jogo, os alunos inseriram os desafios de matemática como forma de obstáculo a ser enfrentado. Ao resolver o problema, o jogo teria seu prosseguimento.

A finalização do trabalho ocorreu no Scratch Day, em que os alunos socializaram suas produções. Os familiares participaram valorizando a produção de seus filhos, e apoiaram a estratégia de integrar os jogos à educação.

Na semana após o evento, para dar continuidade ao processo de avaliação, os alunos do $5^{\circ}$ ano responderam novamente às questões do GameFlow, para verificar se contemplaram o que haviam planejado inicialmente. Em seguida, reformularam seus jogos com as observações obtidas com a avaliação.

\section{Resultados}

A avaliação baseada nas dimensões do GameFlow favoreceu muito os alunos no desenvolvimento do planejamento e na avaliação dos próprios jogos.

Na primeira avaliação dos jogos criados por outros alunos, a questão para analisar os dados de diversão e "vontade" de continuar jogando, envolveu questões como o tempo de duração do jogo, pois os alunos apontaram que o jogo demorava muito, por isso a maioria não jogaria novamente, mesmo sendo um jogo legal (Fig. 1). 
V Congresso Brasileiro de Informática na Educação (CBIE 2016)

Anais do XXII Workshop de Informática na Escola (WIE 2016)

Quando acabou o jogo, você queria jogar mais?

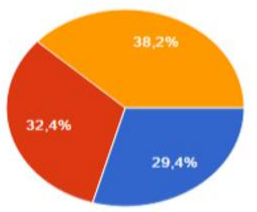

U jogo TOl alvertıao? (34 respostas)

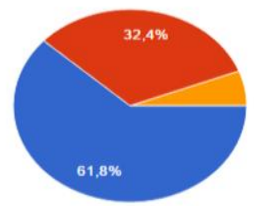

Fig. 1 Resultado da avaliação de jogo em relação à diversão

Já as questões que analisaram os desafios de matemática, nas duas análises demonstradas na Fig. 2, os alunos reconheceram que a dificuldade estava nas questões com enunciados grandes, os quais dificultavam a leitura, chegando à conclusão de que no jogo deles, deveriam criar desafios mais objetivos.

Foi possível responder os desafios de matemática?

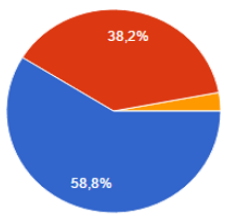

No decorrer do jogo a dificuldade dos desafios de matemática aumentou?

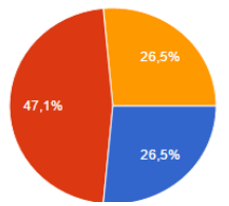

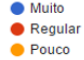

Fig. 2 Questões que analisaram os desafios de matemática

Em relação a verificar o progresso do jogador e a pontuação, os alunos comentaram as estratégias que utilizaram para buscar indícios do progresso, mesmo sem a existência de um placar:

Aluno 5: Lá não tinha pontuação, mas quando você acerta, você visualiza e consegue contar o número de acertos. Mas não perde e nem ganha pontos.

Aluno 6: Não tinha pontuação, mas se chegasse até o fim sabia que acabou acertando tudo. Mas faltou um marcador de ponto, pois não é possível saber a quantidade de erros.

A avaliação mais curiosa que demonstrou claramente o ponto de vista dos alunos foi em relação à possibilidade de multiusuários. $\mathrm{O}$ jogo avaliado foi criado apenas para um jogador, mas na avaliação, $76,5 \%$ responderam que era possível jogar com mais de um jogador, verifique a justificativa do aluno 9:

Aluno 9: Sim, porque jogamos em duplas. E, se tiver mais pessoas, conseguimos resolver mais fácil as questões e terminar mais rápido.

Isso demonstrou que não era necessário o jogo oferecer a possibilidade de multiusuários ou ser planejado como um jogo colaborativo, pois eles conseguiram se organizar no jogo desta forma, porém, apontaram como uma possibilidade interessante, que foi revelada na criação dos jogos de alguns grupos.

A experiência de avaliar os jogos antes da elaboração do roteiro, influenciou o processo de criação da narrativa do jogo, pois os alunos buscaram estratégias que pudessem tornar o jogo mais divertido e atrativo, além disso, eles se preocuparam em desenvolver desafios matemáticos coerentes com a proposta do jogo e, que fossem ao mesmo tempo difíceis, porém, possíveis de serem realizados. 
V Congresso Brasileiro de Informática na Educação (CBIE 2016)

Anais do XXII Workshop de Informática na Escola (WIE 2016)

Os resultados em relação ao avanço das habilidades de resolução de problemas, raciocínio lógico-matemático e capacidade de criação, foram mensurados ao avaliar o desempenho dos alunos durante e após o processo de trabalho. A criação do jogo serviu como um caráter motivador para a produção dos desafios, uma condição de extrema importância para aprendizagem dos alunos.

$\mathrm{Na}$ fala do aluno 1, podemos notar que o trabalho foi desafiador e, ao mesmo tempo, divertido, enquanto na fala do aluno 3, verificamos a parte lúdica ao criar os desafios de matemática aliado ao personagem escolhido:

Aluno 1: No começo foi um desafio criar os problemas, só que depois com o tempo (...), eu consegui criar um dos dois problemas, foi engraçado... (...) E assim, com estes problemas podemos estudar Matemática.

Aluno 3: Foi bem legal criar os personagens, (...). E pensar no desafio matemático foi mais legal, porque a gente escolhia o personagem e inventava os problemas, foi bem divertido!

Contudo, alguns alunos tiveram dificuldades na criação e precisaram de orientação, assim, alguns dos problemas foram baseados nas fontes sugeridas pela professora e por eles consultadas.

Alguns grupos criaram jogos para mais de um jogador devido a discussão que ocorreu na avaliação inicial e os alunos gostaram da proposta, conforme é possível verificar no depoimento do aluno 2:

Aluno 2: Achei interessante a criatividade! Uma das coisas interessantes que você faz no Scratch, teve jogo de multiplayer, ou de um jogador. É como se você jogasse de 2 , 3 ou 4 ... o número que você escolher... daí isso é bom, porque você não fica lá sozinho...

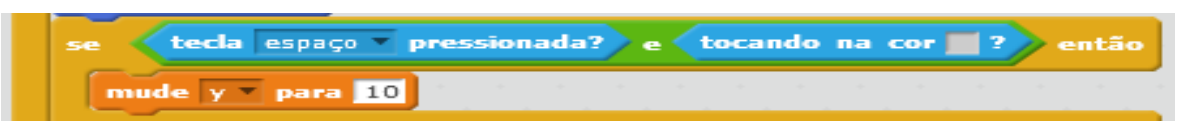

Fig. 3 Comandos para movimentação do personagem Pac Man, criado pelo grupo 3 do $5^{\circ}$ ano A

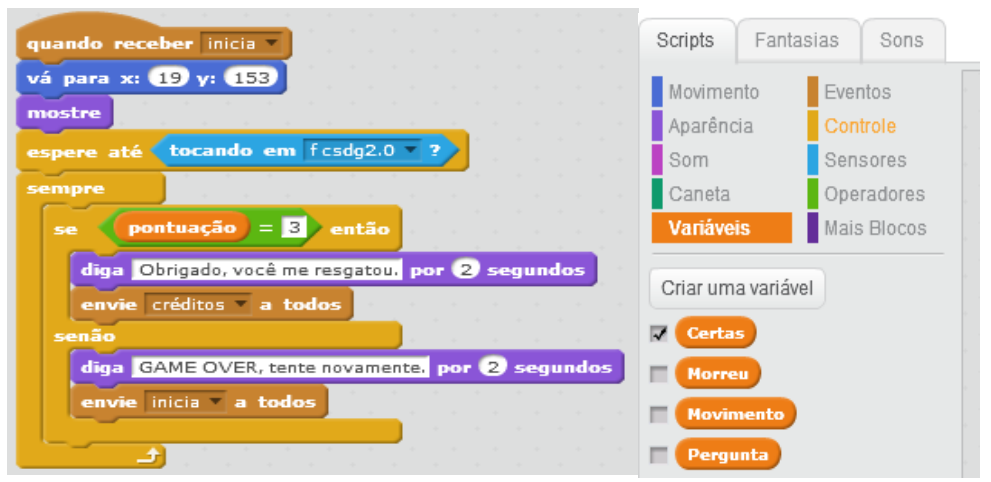

Fig. 4 Dir. Comandos do personagem Pac Man, criado pelo grupo 4 do $5^{\circ}$ ano A e Esq. Variáveis criadas pelo grupo 2 do $5^{\circ}$ ano $\mathrm{A}$, para programar as estratégias de pontuação.

Observou-se, em relação à programação, que o desencadeamento das ações esteve relacionada ao conceito matemático de posicionamento cartesiano, "mude y para 10" (Fig.3), os alunos programaram o salto do pacman, sendo y a "altura" do salto. Também 
outros conceitos foram desenvolvidos como a utilização das variáveis "sempre", "se" e "senão".

Ainda em relação aos avanços na aprendizagem de programação, após avaliar a necessidade, os alunos preocuparam-se em utilizar algum recurso de pontuação, acrescentado a programação com variáveis (Fig. 4), a qual não foi utilizada pelos alunos do ano anterior que produziram os jogos que foram avaliados.

\section{Considerações finais e trabalhos futuros}

A programação dos jogos aliada a temas de interesse escolhido pelos alunos, favorece o envolvimento e o desenvolvimento de uma aprendizagem significativa. Com o propósito de produzir os jogos, a criação de desafios de matemática torna-se prazerosa, pois tem uma finalidade e um receptor real, demonstrando ser uma experiência rica para o desenvolvimento da aprendizagem da matemática, favorecendo o aumento da capacidade de raciocínio lógico, além de propiciar o letramento digital, por meio do qual os alunos deixam de ser meros consumidores de softwares educativos, passando para uma postura de criadores de jogos, no contexto de um processo verdadeiramente significativo.

Em Matemática, a produção dos desafios matemáticos foi considerada como instrumento de avaliação. Criar problemas é uma ação mais complexa do que resolver problemas, revela se há ou não domínio dos conceitos matemáticos. Pelos dados obtidos, o professor pode planejar novas estratégias e possibilidades de aula para auxiliar os alunos em suas dificuldades. A interação com professor e colegas e o acesso a um repertório de resolução problemas são fundamentais para o percurso da autoria que se adquire com tempo, prática e reflexão.

A avaliação dos jogos nos dois contextos aplicadas (seja como forma de reflexão para a criação inicial seja como avaliação da produção) foi significativamente positiva tanto para a criação da narrativa do jogo e elaboração de estratégias, quanto para uma análise das diferentes possibilidades do jogo e do seu potencial de oferecer uma experiência agradável ao jogador, demonstrando que é possível aplicar a teoria de GameFlow com os alunos na busca de uma produção de jogos aliada à uma aprendizagem cada vez mais significativa.

Como trabalhos futuros, os alunos poderão desenvolver outros projetos, integrando os saberes adquiridos em relação a programação com os diversos conteúdos curriculares.

\section{Referências}

Andrade,M.; Silva,C; T. Desenvolvendo games e aprendendo matemática utilizando o Scratch. In: Simpósio Brasileiro de Jogos e Entretenimento Digital. São Paulo,2013.Proceedings do XII SBGames: Culture Track - Short Papers. São Paulo: SB Games, 2013, p.260-263. Disponível em: <http://www.sbgames.org/sbgames 2013/proceedings/cultura/Culture-5_short.pdf> Acesso em 24 de maio de 2016

Bittencourt, Ig Ibert; Santos, Wilk Oliveira dos; Neto, Sebastião Rogerio da Silva; Silva Junior, Clovis Gomes da. Avaliação de Jogos Educativos: Uma Abordagem no Ensino de Matemática. Anais do XXVI Simpósio Brasileiro de Informática na Educação 
V Congresso Brasileiro de Informática na Educação (CBIE 2016)

Anais do XXII Workshop de Informática na Escola (WIE 2016)

(SBIE 2015) Disponível em: <http://www.br-ie.org/pub/index.php/sbie/ article/view/5334> Acesso em 26 de maio de 2016.

Csikszentmihalyi, Mihaly. (1993). The evolving self: A psychology for the third millennium. New York: Harper Perennial.

Fu, Fong-Ling; Su, Rong-Chang; Yu, Sheng-Chin. EGameFlow: A scale to measure learners' enjoyment of e-learning games. Computers \& Education 52 (2009).

Maltempi, Marcus Vinicius; Vecchia, Rodrigo Dalla; Sapiras, Fernanda Schuck. Utilização do Scratch em sala de aula.Educação Matemática e Pesquisa (ISSN 19833156), São Paulo, v.17, n.5, p.973-988, 2015 Disponível em: <http://revistas. pucsp.br/index.php/emp/article/view/25152> Acesso em 18 de maio de 2016.

Medeiros, Maxwell de Oliveira; Schimiguel, Juliano. Uma abordagem para avaliação de jogos educativos: ênfase no ensino fundamental. Anais do $23^{\circ}$ Simpósio Brasileiro de Informática na Educação (SBIE 2012). Disponível em: < http://www.brie.org/pub/index.php/sbie/article/view/1787> Acesso em 26 de maio de 2016.

Neves, Daniel Eugênio; Santos, Luana Giovani Noronha de Oliveira; Santana, Renata Cristina; Ishitani, Lucila. Avaliação de jogos sérios casuais usando o método GameFlow. Revista Brasileira de Computação Aplicada (ISSN 2176-6649), Passo Fundo, v. 6, n. 1, p. 45-59, abr. 201445 Disponível em: <http://www.upf.br/ seer/index.php/rbca/article/view/3244/2552> Acesso em 26 de maio de 2016.

Pinto, António Sorte. Scratch na aprendizagem da Matemática no $1^{\circ}$ Ciclo do Ensino Básica: estudo de caso na resolução de problemas. Dissertação de Mestrado. Universidade do Minho. Disponível em: <http://hdl.handle.net/1822/14538> Acesso em 26 de maio de 2016.

Shimohara, Cintia; Sobreira, Elaine Silva Rocha. Criando Jogos Digitais para a aprendizagem de matemática no ensino fundamental I. Anais do XXI Workshop de Informática na Escola (WIE 2015). Disponível em: <http://www.br-ie.org/pub/ index.php/wie/article/view/4994/3404> Acesso em 26 de maio de 2016.

Silva, Tatyane S. C. da; Melo, Jeane C. B. de; Tedesco, Patricia C. de A. R. A Teoria do Flow na contribuição do engajamento estudantil para apoiar a escolha de jogos no ensino de programação. Anais do XXVI Simpósio Brasileiro de Informática na Educação (SBIE 2015). Disponível em: <http://www.br-ie.org/pub/index. php/sbie/article/view/5324/3687> Acesso em 26 de maio de 2016.

Sobreira, Elaine Silva Rocha; Takinami, Olga Kikue; Santos, Verônica Gomes dos. Programando, Criando e Inovando com o Scratch: em busca da formação do cidadão do século XXI. Anais da II Jornada de Atualização em Informática na Educação (JAIE 2013). Disponível em <http://br-ie.org/pub/index.php/pie/article/view/ 2592/2248>. Acesso em 26 de maio de 2016.

Ramos, Fellipe Oliveira; Teixeira, Lilian da Silva. Significação da Aprendizagem Através do Pensamento Computacional no Ensino Médio: uma Experiência com Scratch. Anais do Wie, 2015. Disponível em: <http://www.brie.org/pub/index.php/wie/article/view/5024/3434>. Acesso em 26 de maio de 2016. 